\title{
Vulnerability to multiple stressors in coastal communities: A study of the Andaman Coast of Thailand
}

\author{
Nathan J. Bennett, Philip Dearden, Ana Maria Peredo
}

This is a post-print version of the following article: Bennett, N.J., Dearden, P., \& Peredo, A.M. (2014). Vulnerability to multiple stressors in coastal communities: A study of the Andaman Coast of Thailand. Climate and Development

\begin{abstract}
:
Vulnerability and adaptation to climate change has become a dominant theme in development and conservation research and work. Yet coastal communities are facing a wider array of different stressors that affect the sustainability of natural resources and the adaptive capacity of local residents. The ability of communities and households to adapt is influenced by the nature, number, and magnitude of the changes with which they have to contend. In this paper, we present the range of 36 socio-economic (i.e., economic, social, governance and conflict) and biophysical (i.e., climate change and other environmental) stressors that emerged from qualitative interviews in 7 coastal communities on the Andaman coast of Thailand. These stressors were then integrated into a quantitative survey of 237 households wherein participants were asked to rate the level of impact of these stressors on household livelihoods. Ratings showed that economic and some climate change stressors - extreme weather events and changes in rainfall patterns and seasons - were scored higher than other stressors. The paper also examines the relationships between community and various individual and household characteristics such as gender, age, livelihoods, levels of social capital, and socio-economic status - and the perceived level of impacts of various stressors on household livelihoods. Overall, community and livelihoods had the most differentiated impacts on perceptions of stressors but few other prominent patterns emerged. In conclusion, this paper discusses the implications of the results for current climate change vulnerability and adaptation policy and practice in Thailand and elsewhere.
\end{abstract}

Keywords: vulnerability, adaptation, multiple stressors, exposure, coastal communities

\section{Introduction}

Climate change related events, including ocean warming, sea level rise, more intense storms, storm surges, changes in ocean circulation, and ocean acidification, threaten the health and productivity of marine ecosystems and the well-being of coastal communities (Brierley \& Kingsford, 2009; HoeghGuldberg \& Bruno, 2010; Parry \& IPCC, 2007). Coastal and island communities are particularly vulnerable to the impacts of climate change due to their direct reliance on the goods and services provided by marine ecosystems, the proximity of houses and infrastructure to rising seas and extreme weather events, and the increasing unpredictability of weather patterns. For this reason, a significant amount of attention has been paid to climate change vulnerability and adaptation policy and practice relating to this context (Klein \& Patt, 2012; Marshall et al., 2010; McClanahan \& Cinner, 2011; USAID, 2009; Wongbusarakum \& Loper, 2011).

However, the climate change adaptation discourse has become so dominant in conservation and development policy and practice that practitioners and policy makers may neglect to incorporate the wide array of stressors that are facing coastal communities. The stressors facing coastal communities, and associated ecosystems, include social, economic, institutional, political, demographic, livelihood, and other environmental changes (Perry et al., 2010; Zou \& Wei, 2010). Many authors have argued that it is important to understand the interactions between global environmental changes, including climate 
change, and other social, economic, and political changes occurring at multiple spatial and temporal scales in order to create effective adaptation policy (e.g., O’Brien \& Leichenko, 2000; Silva et al., 2010; Turner et al., 2003). Hjerpe and Glass (2012, p 471), for example, state that the omission of socioeconomic stress "leads to critical weakness in local adaptation strategies". A nuanced understanding of the multiple stressors facing communities and coastal ecosystems can allow for the design and prioritization of adaptive strategies to address one or more stressors in order to reduce overall vulnerability of communities.

Similar to elsewhere in the world, coastal communities on the Andaman coast of Thailand have experienced rapid social, economic, environmental, and climatic changes, which will be described in detail later in the paper. It is within this context of rapid socio-economic and biophysical change that the current study was conducted. This particular study is part of a broader project that explored the impacts of climate change on communities, the relationship between local communities and marine protected areas, and the adaptive capacity of communities (see also Bennett, 2013; Bennett \& Dearden, 2013a, 2013b; Bennett, Dearden, Murray \& Kadfak, in press). In order to set the context for explorations of adaptive capacity and to understand how significant climate change is perceived to be, we explored the broader array of changes and stressors that communities are experiencing. This paper focuses on qualitative perceptions of the stressors that communities are exposed to, quantitative perceptions of how sensitive households are to these stressors, and potential differential impacts of stressors across communities, households, and groups.

The paper proceeds as follows. First, it briefly reviews theory from the extensive literature on vulnerability, including an introduction to exposure, sensitivity, and adaptive capacity, and describes the context and study sites. Subsequently, we explain the methods used in this study including interviews and surveys followed by an examination of qualitative descriptions of stressors from the interviews, quantitative ratings of stressors from household surveys, relationships between community and household and individual characteristics and perceived impacts. In conclusion, we discuss the implications of these results for climate change adaptation policy and practice related to both development and conservation in Thailand.

\section{Theoretical Framework: Vulnerability to Multiple Stressors}

Recent academic and applied literatures on global environmental change, marine conservation, and fisheries have focused extensively on vulnerability (e.g., Füssel, 2007; Adger \& Kelly 2001; McClanahan \& Cinner, 2011; Parry \& IPCC, 2007). Vulnerability is currently conceptualized in several ways (Adger, 2006). In the first view, the focus of vulnerability analysis is on the "end-point" impacts of climate change and the effectiveness of adaptation measures (Ensor \& Berger, 2009; Kelly \& Adger, 2000). The goal of this approach is to estimate and reduce the costs of climate change impacts. The second view of vulnerability emphasizes the "starting point" through examinations of the characteristics of households, communities, or regions that make them susceptible to change. For example, Vogel (1998, p 15) saw vulnerability as a "function or characteristic of people and groups that influences their capacity to anticipate, cope with, resist, and recover from the impacts of change" and the IPCC defines vulnerability as "the degree to which a system is susceptible to, or unable to cope with, adverse effects of climate change" (McCarthy \& IPCC, 2001, p 995). These and similar definitions of vulnerability position it in such a way that it is either akin to or the flipside of adaptive capacity (defined below).

The third way of seeing vulnerability is more comprehensive and integrated - conceptualizing vulnerability as a function of interactions between three elements: exposure, sensitivity, and adaptive capacity (Adger, 2003; Marshall et al., 2010; Tuler et al., 2008; Turner et al., 2003). Vulnerability is seen as depending partly on exogenous change occurring at various scales and partly on localized social capacity and technical infrastructure (Eakin, 2005; Leichenko \& O'Brien, 2008). In this view, exposure refers to the presence of and extent to which stressors - various changes occurring at different scales that 
cause stress - are experienced by a region, resource, or group (Marshall et al., 2010). Sensitivity is the degree to which a system is affected by or harmed by exposure to a stressor (Marshall et al., 2010; Tuler et al., 2008). Turner et al. (2003) suggest sensitivity is related to local social and environmental conditions. The combination of exposure and sensitivity define the potential impact of a stressor (Figure 1). Adaptive capacity - which determines the ultimate impact of a stressor or the overall level of vulnerability - can be defined as "the ability to respond to challenges through learning, managing risk and impacts, developing new knowledge and devising effective approaches" (Marshall et al., 2010, p 5). An integrated view of social vulnerability requires an understanding of exposure - the types and extent of stressors that are facing the system - to inform assessments of adaptive capacity and adaptation plans (Brklacich et al., 2010). In other words, comprehensive vulnerability assessments require examinations of "how?", "why?", and "to what?" people and communities are vulnerable.

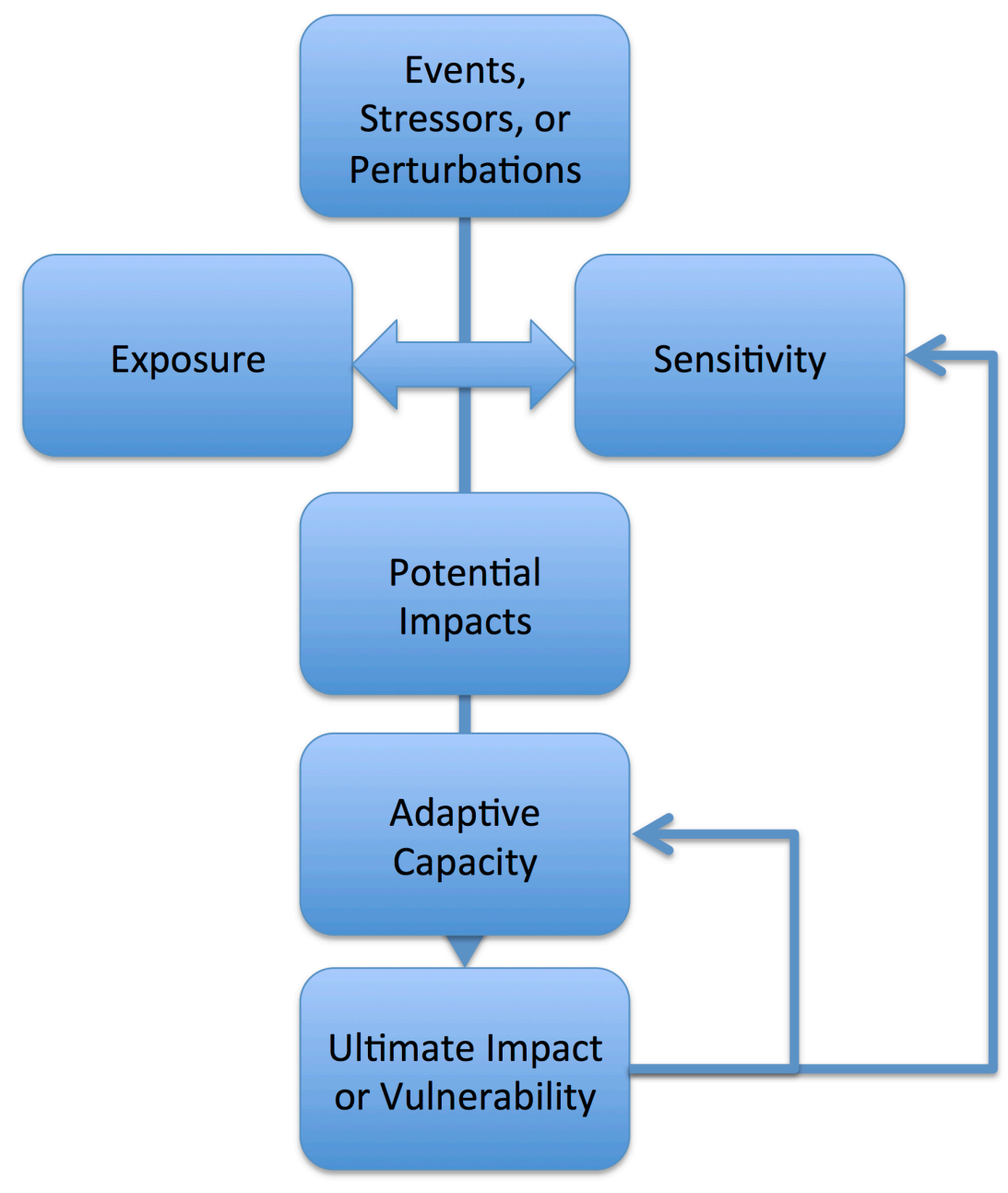

Figure 1 - Vulnerability as a function of exposure and sensitivity to stressors and adaptive capacity (Adapted from Turner et al., 2003; Marshall et al., 2010)

In previous research on vulnerability, the impacts of biophysical and socio-economic stressors are often examined in isolation (Reid \& Vogel, 2006). Yet, there is broad recognition that coastal communities are undergoing a wide array of changes - social, cultural, economic, political, and environmental (e.g., Blythe, 2013; Bunce, Rosendo \& Brown, 2010; McCubbin, 2013; Moerlein \& Carothers, 2012; Ommer \& Team, 2007; Perry et al., 2010; Perry et al., 2011; Tuler, 2008; see Zou \& 
Wei, 2010 for a review). Coastal communities are particularly sensitive to the impacts of climate change, which has led to increasing storm events, storm surges, and erosion and impacts on infrastructure, saltwater intrusion into freshwater areas, impacts on ecosystems and species that are important for livelihoods, and changes in seasons and rainfall patterns leading to less predictability (see McClanahan \& Cinner, 2011). Explicit recognition of multiple stressors and socio-economic stress is essential for successful adaptation planning and policy (Hjerpe \& Glaas, 2012). The theory of "double exposure" recognizes that there are multiple stressors that are simultaneously impacting individuals, communities, groups, or sectors and interacting to produce both positive and negative outcomes (Leichenko \& O'Brien, 2008; O'Brien \& Leichenko, 2000). Most work in this area focuses on the dual impacts of stressors related to economic globalization and global environmental change (Eakin, 2005; Leichenko \& O'Brien, 2002; O'Brien et al., 2004). However, some authors apply the term more loosely to refer to the coupled impacts of global environmental change and any other socio-political changes that are occurring or simply discuss multiple stressors (Bunce, Rosendo, et al., 2010; Mubaya et al., 2012; Reid \& Vogel, 2006). Double exposure theorists also point out that there are differential impacts of stressors - i.e., that some individuals, groups, households, or communities may be more or less exposed to, sensitive to, or able to adapt to one or multiple stressors (O’Brien \& Leichenko, 2003; Tuler et al., 2008).

In proposing the "double exposure" framework, Leichenko and O'Brien (2000) identified the need for both qualitative and quantitative analysis on exposures including case studies, comparative work, and cross-scalar examinations. Though a growing body of work on multiple exposures and double exposure has emerged since 2000 (e.g., Mubaya et al., 2012; Paavola, 2008; Silva et al., 2010), Zou and Wei (2010, p 919) suggest that there is still a "tremendous gap between conceptual theoretical work on vulnerability and empirically based case studies." Indeed there are still relatively few examinations of how global environmental changes are experienced by local social systems, individuals, or communities with the focus instead being on clarifying uncertainties in global to regional models (Barnett et al. 2010), which "capture neither the complex experiences nor the uneven distributions of vulnerabilities within heterogenous communities" (Brklacich et al., 2010, p 47). Bunce et al (2010, p 408) also argue that "There is a critical need to investigate and illuminate how these multiple stressors may affect the ability of households and communities to respond to climate change, and how it will affect their ability to secure and sustain livelihoods, future well-being, and life opportunities." These authors all argue for increased focus on place-based analysis and echo earlier writings suggesting the need to focus on the perspectives of "the vulnerable" (Chambers, 1984; Chambers, 1995; Eakin, 2005). Holistic understandings of vulnerability have also lead social scientists to explorations of human perceptions (Brklacich et al., 2010). A focus on local perspectives in vulnerability and adaptation research is apposite since perceptions of risk can determine adaptation or coping measures and lead to actions to reduce risk (Mubaya et al., 2012; Tuler et al., 2008). Furthermore, a focus on structural causes, impacts, or responses to change suggests a passive or static understanding of vulnerability - which deemphasizes human agency and the role that this plays in mediating and responding to stressors or changes. Differentiating between the perspectives of different groups is also important for understanding how they are differently impacted by change. Our reviews of previous literatures in the field show there has been limited empirical study of either the multiple stressors that are being experienced by coastal communities from the perception of local people or the differential impacts of these stressors.

\section{Context}

\section{Andaman Coast of Thailand}

Coastal communities on the Andaman coast of Thailand have experienced rapid socio-economic and biophysical changes over the last few decades due to a variety of factors. The 500-kilometer stretch of coast, situated between Malaysia and Myanmar on the Bay of Bengal and encompassing approximately 
$116,000 \mathrm{~km}^{2}$ of marine area is recognized as being ecologically significant and high in biodiversity and productivity with important areas of seagrass, coral reefs, and mangroves (Juntaroshte, 2005; World Bank, 2006). The six coastal provinces on the Andaman coast were home to over 2 million people living in several larger centers and over 1800 villages, including 621 fishing villages (Panjarat, 2008). Livelihoods in the region consist mainly of fisheries, agriculture and plantations, and tourism.

At a national level, Thailand has experienced rapid economic growth and expansion of industries with annual growth of exports exceeding 30\% annually during the 1990 s and rapid growth of foreign investments (Leinbach \& Ulack, 2000). According to the World Bank, Thailand's Gross National Income (GNI) per capita has risen from US\$1870 in 1992 to US\$4420 in 2011 (World Bank, 2012). The 2004 Millennium Development Goals Report for Thailand shows that overall well-being has rapidly improved - particularly in the areas of poverty, gender equality, HIV/AIDS, and malaria - but points out that disparities persist and that rural regions in particular still need improved infrastructure, education, and health programs (UNDP, 2005). Partially as a result of economic growth and opportunity, Thailand, like much of Southeast Asia, has experienced rapid urbanization and internal migration and in-migration (Leinbach \& Ulack, 2000). Politically, recent years have seen a significant number of changes of power in Thailand - which has often resulted in political unrest and demonstrations in Bangkok (Baker \& Phongpaichit, 2009).

Rapid economic and population growth in Thailand has long threatened the health and productivity of the environment (Rigg, 1995). The main threats to the marine environment on the Andaman Coast include degradation of habitats, overexploitation of resources, and pollution (BOBLME, 2010).

Extensive commercial fisheries and small-scale fleets that serve both domestic and international markets have lead to overfishing for the past few decades and caused fisheries declines in territorial seas on the Andaman (see Panjarat, 2008). Partially in response to changing environmental conditions, a system of 18 marine protected areas under national jurisdiction were created in this area (World Heritage Nomination Document, 2010). Alongside the other environmental changes, climate change is already having very real impacts in the region and it is projected that climate change impacts will increase. For example, Thailand's coral reefs have experienced coral bleaching events in 1991, 1995, 1998 and in 2010 a severe coral bleaching event resulted in between $25-99 \%$ mortality of corals across reefs in the region (Phongsuwan, 2011). Regional models and forecasts suggest that climate change will result in increased maximum and minimum temperatures (greater than $3^{0} \mathrm{C}$ ), more warm days, increased precipitation (8\%), more intense rainfall in the rainy season, and longer dry seasons (START, 2010). Sea level is expected to rise by $1-2 \mathrm{~mm}$ annually (Unnikrishnan \& Shankar, 2007). This region was also impacted by the 2004 tsunami, which had a significant physical impact on some coastal communities and also brought relief and reconstruction efforts (along with associated NGOs, church groups, foreign aid and corruption) and for some communities brought about shifts in livelihoods (Lebel, Khrutmuang \& Manuta, 2006).

\section{Study Sites}

This study used a multiple case study approach. Seven communities were chosen for insight on the basis of the following criteria: proximity to a marine protected area, diversity of livelihood portfolios, range of levels of dependence on fishing for livelihoods and subsistence, varied levels of wealth, proximity to a variety of marine habitat types including mangroves, coral reefs, and seagrass areas, different ethnic groups and population sizes (see Table 1 and Table 3). All of the communities chosen were on islands. Financial and temporal feasibility were also taken into account when choosing the number of communities and the choice to conduct an insight-based rather than a generalizable study. The multiple case study approach used in this study allowed for a comparison of households and communities with different livelihood mixtures, ethnic backgrounds, and ecosystem dependencies but generalizability cannot be assumed. The seven communities included in this study are Baan Tha Khao 
and Baan Koh Panyee in Ao Phang-Nga, Baan Lions and Baan Tapae Yoi on Koh Phrathong, Baan Koh Chang and Baan Moken on Koh Chang, and Baan Koh Sin Hi in Ranong (Figure 2; Note:

Baan=Village; Koh=Island; Ao=Bay).

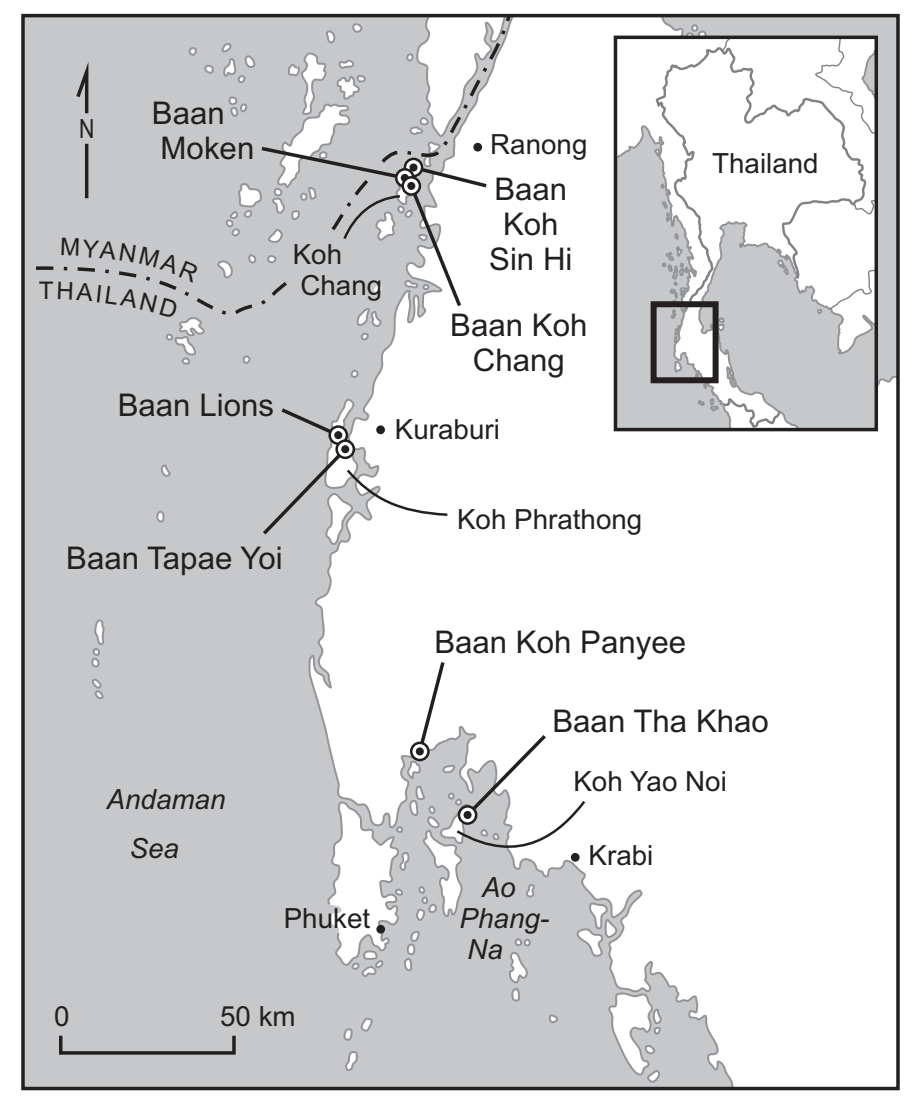

Figure 2 - Map of Study Sites on the Andaman Coast of Thailand

Baan Tha Khao is situated in Ao Phang-Nga on the small island of Koh Yao Noi, is a small community (pop. 486; Koh Yao Island Health Centre) primarily Muslim community that relies on fishing, rubber tapping, and tourism for livelihoods. Locals tend to own their own boats for fishing, land for rubber, and bungalows for tourism rather than working for other people. Fishers from Bhan Tha Khao primarily fish near a number of reefs in Ao Phang-Nga. Due to the popularity of the karst formations (including James Bond Island popularized after being included in the 1974 movie Man with the Golden Gun), beaches and snorkeling in Ao Phang-Nga, the "floating" Muslim community of Baan Koh Panyee (pop. 1440; Community Health Centre) has become highly dependent on day-trip tourism through sales, restaurants, and sea canoe tours. The island can receive as many as 1000 tourists in a day (interviews) with the national park in which it is situated receiving up to 202,808 visitors annually (World Heritage Nomination Document 2010). Fishing and fish-cage aquaculture remain important livelihoods for a smaller portion of the community.

After Baan Pak Jok was destroyed in the 2004 tsunami, Lions International built the village of Baan Lions (pop. 57; Ko Phrathong Health Centre) further inland on Koh Phrathong with a pier in a nearby mangrove canal. Currently, only 44 of the 165 houses in the community are occupied and the school is not in operation. For many inhabitants, finding employment is a problem with the majority of the remaining population working in fishing, tourism, and agriculture. There is also a growing communitybased tourism group that has been supported by Andaman Discoveries and Mangrove Action Project (see Andaman Discoveries 2012). About 4 kilometers away via motorbike track on Koh Phrathong, 
Baan Tapae Yoi (pop. 119; Ko Phrathong Health Centre) is a community of mixed Buddhist and Moken ancestry that was not heavily impacted by the tsunami. Many residents still rely on fishing but they are increasingly reliant on wage labor.

The resident population of Baan Koh Chang (pop. 300; key informant interview) is primarily involved in agriculture (rubber and cashew plantations) and small-scale tourism development (bungalows on the beach) with fewer households relying on fisheries. Situated at the far northern end of Koh Chang, Baan Moken (pop. 175; key informant interview) was built by a Christian missionary group from the United States in conjunction with a Christian group from Thailand after the tsunami. The community is occupied by a group of stateless Moken - a nomadic indigenous group that lived on the Andaman coast between Myanmar, Thailand, and Malaysia (see Arunotai 2006; UNESCO 2007). Though their previous village on Baan Koh Lao had been little effected by the tsunami, the new community allowed a segment of the population from the over-crowded old village to claim new homes on the island. This also allowed them to "escape" from previous working arrangements and indebtedness to a wealthy Thai family on Baan Koh Lao (anonymous interviewee). Most of the community relies on crab fishing on several nearby reefs, collection of recyclable plastics, and subsistence harvesting in mangrove areas and on nearby islands. Finally, Baan Koh Sin Hi (pop. 1775; Community Health Centre) is located on an island north of Koh Chang and west of Ranong city near the unresolved maritime border with Myanmar. This community contains a mixture of people of Malaysian, Thai, and Burmese descent who rely primarily on fishing - often across the border in Myanmar - and temporary out-migration to do wage labour in construction and agriculture.

Table 1 - Community information and survey sample

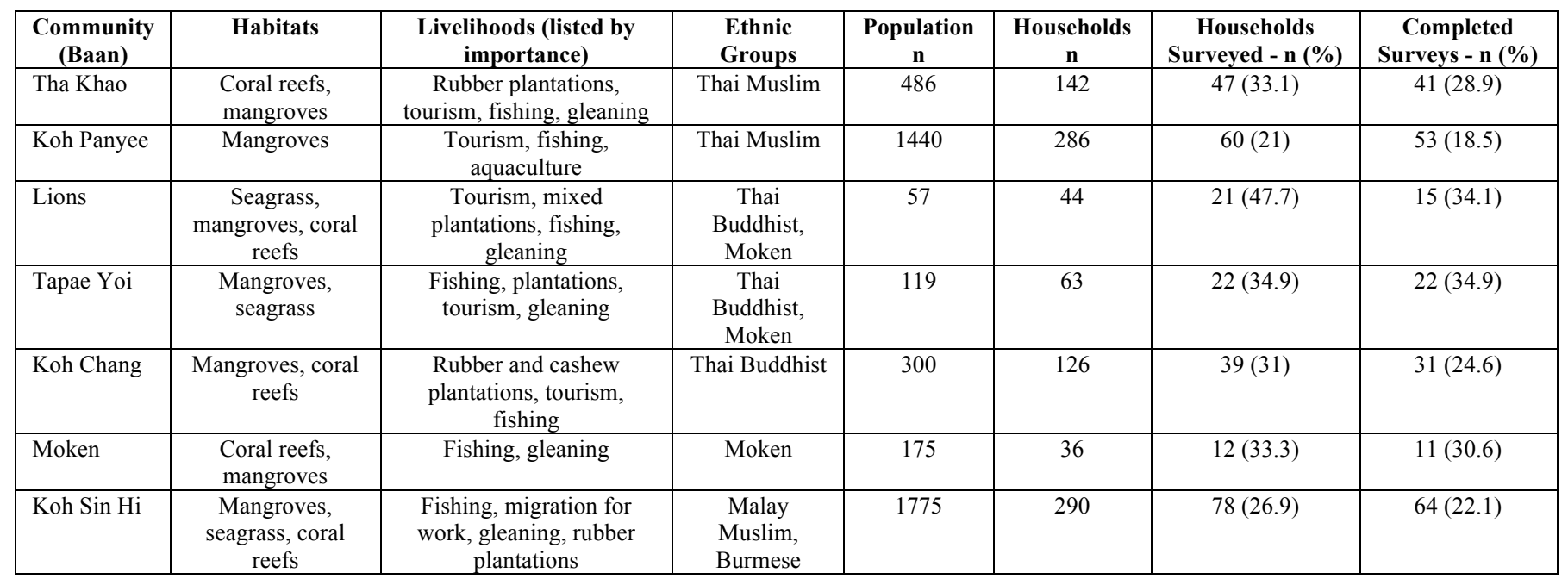

\section{Methods and Sampling}

This study used a mixed-methods approach, including both qualitative interviews and quantitative surveys. Interviews were structured around this study's broader themes: the impacts of social-ecological change on communities, the adaptive capacity of communities to change, and the impact of marine protected areas on communities (Bennett, 2013; Bennett \& Dearden, 2013a, 2013b; Bennett, Dearden, Murray \& Kadfak, in press). Part of the interview focused on the types of social and ecological changes that were being experienced by households and communities on the Andaman coast. Participants were also asked to specify if the changes had a negative or positive impact on their households or the 
communities. Negative changes - or stressors - that emerged during these interviews were coded thematically and incorporated into the survey.

The survey part of this study included a random sample of households in each of the 7 communities. Due to shortages of household lists or community maps, household maps were hand-drawn for each community. A member of our survey team who was not familiar with the community would then randomly select every $\mathrm{n}^{\text {th }}$ house. By selecting the $\mathrm{n}^{\text {th }}$ house spatially across the community map, we were able to include households from different ethnic, livelihood and family groupings who were generally located in spatial clusters. Depending on size of the community, we selected between every $2^{\text {nd }}$ to $5^{\text {th }}$ house to obtain a reasonable sample size. Surveys were conducted with one person in the household (the interviewee) based on availability and self-selection.

The survey questions included individual (e.g., interviewee's ethnicity, age, gender, occupation) and household level characteristics (e.g., household income, assets, livelihoods, ethnicity, number of people), various indicators of adaptive capacity, and perceptions of the effects of national parks on the community. One aspect of the survey focused specifically on the perceived level of impact of the stressors on household livelihoods using the list of coded stressors that emerged from the interviews. Survey participants were asked to rate a list of 36 stressors (see Figure 3) on a Likert scale from 1-5 where $1=$ no impact, $2=$ very little impact, $3=$ medium level of impact, $4=$ high level of impact, $5=$ very high level of impact, and $6=$ don't know. Prior to conducting the surveys, all sections were translated from English to Thai and back-translated by a different translator from Thai to English to ensure accuracy. Discrepancies were rectified and an additional stage of forward and back translation was done. The surveys were also pilot tested in two different communities and changes were made to the survey based on feedback of test participants and surveyors. For example, at this stage we excluded "tsunami" from the list of stressors as test participants suggested that the tsunami was manifold times more impactful than any of the other stressors and surveyors felt that it would skew the results. Surveys were conducted by trained Thai field staff. The field staff completed the paper surveys and then doublechecked their results after each field visit.

Paper surveys were coded and entered in an electronic format by a data entry company and $10 \%$ of the surveys were double-entered to ensure accuracy. After data entry, the survey data was imported into SAS v9.1 (SAS Institute, Carey NC) for additional data cleaning and all subsequent analysis. Descriptive statistics were generated for each individual survey interviewee and for household level characteristics. For each stressor, mean scores for all participants and sites were calculated to determine generalized impacts. Subsequently, means scores for each community were calculated and compared using ANOVA to explore how community, household and individual level factors relate to perceived impacts. A range of household and individual characteristics (see Appendix A for details) - including household most important livelihood by income, household dependence on fisheries livelihoods, household income, number of household appliances, household land ownership for livelihood purposes, primary occupation of interviewee, age of interviewee, gender of interviewee, level of formal education of interviewee, occupational mobility of interviewee, individual mobility of interviewee, social capital or level of community involvement, and number of climate change information - were also considered as possible predictors of stressor scores using regression (for continuous predictors) and ANOVA (for categorical predictors).

There were several limitations to this research approach. The first is that due to the emergent nature of the research using interviews with a purposive sample we may have missed some stressors. A later participatory stage of research, for example, pointed to several internal socio-economic stressors that were not included in the survey. This included internal population growth, outmigration of youth, changes in regional governance structures, and centralization of wealth and power within communities (Bennett \& Dearden, 2013a). A second limitation is the non-random or comprehensive sample of communities used during the survey, which limits the generalizability of the results. Finally, the wording of several stressors - e.g., "government policies" - may have been unclear. 


\section{Results}

\section{Interview Results: Emergent Socio-Economic and Biophysical Stressors}

We conducted a series of 23 small group community interviews (2-5 people) and 85 individual interviews with a purposive sample of community leaders $(\mathrm{n}=22)$, community group leaders $(\mathrm{n}=5)$, community members $(n=35)$, as well as $\operatorname{NGO}(n=7)$, academic $(n=3)$, and government agency $(n=10)$ representatives from outside the community along the northern Andaman coast of Thailand.

Stressors that emerged from the interviews were characterized as either socio-economic or biophysical. Socio-economic stressors were further categorized under social, economic, or governance and conflict. Social stressors mentioned by participants included the in-migration of people (especially foreign workers) to the area and household health issues. The main economic stressors included rising costs of living, for livelihood supplies, and of gas as well as declining prices and demand for livelihood products. Both rising costs and increasing demands are related to increasing levels of household debt, which may partially be caused by increasing material desires and resultant purchases beyond means. Pertaining to governance and conflict, many types of conflicts were described by participants, including between communities, between groups of small-scale fishers, between small-scale fishers and commercial fisheries, between communities and outside business people encroaching on land, between fishers/harvesters and the tourism industry, within communities, and with fishers who were fishing illegally. Fishers, or their family members, described being arrested or having gear taken when travelling across the border to fish in Myanmar. Interviewees also mentioned various national level policies, including fisheries gear restrictions, declining agricultural subsidies, a focus on only rubber development, and an emphasis on large-scale tourism development, that negatively impacted local development outcomes. The marine national parks were also seen to restrict local livelihoods both on land and at sea. Unrest in Thailand following changes in national governments was also seen to have a negative impact on tourism.

Biophysical stressors were categorized under climate change or environmental. Climate change related stressors mentioned by participants included flooding, saltwater intrusion, rising sea levels, coral bleaching, increasing precipitation leading to inflows of freshwater into mangrove habitats, erosion, changes in rainy and dry season, and increasing storm events. The last three stressors were mentioned the most often by participants - perhaps because they each had the most direct impact on community infrastructure and household assets or on livelihood outcomes. Storm events and seasonal changes were seen to particularly increase the risks for fishers, forcing them to make difficult decisions between loosing gear or endangering life and limb. Other environmental stressors discussed by participants included pollution and garbage in the ocean, sedimentation, landslides and overfishing. Overfishing was used synonymously with declines in fish and catches. Descriptions of the stressors (as they were described by interview participants) and analysis of the scale of the drivers causing the changes are shown in Table 2. As mentioned previously, we chose to remove "tsunami" from the list of stressors as we felt that including this extremely impactful event would skew the survey results. 
Table 2 - Qualitative descriptions of stressors that communities are exposed to including sphere, category, and scale

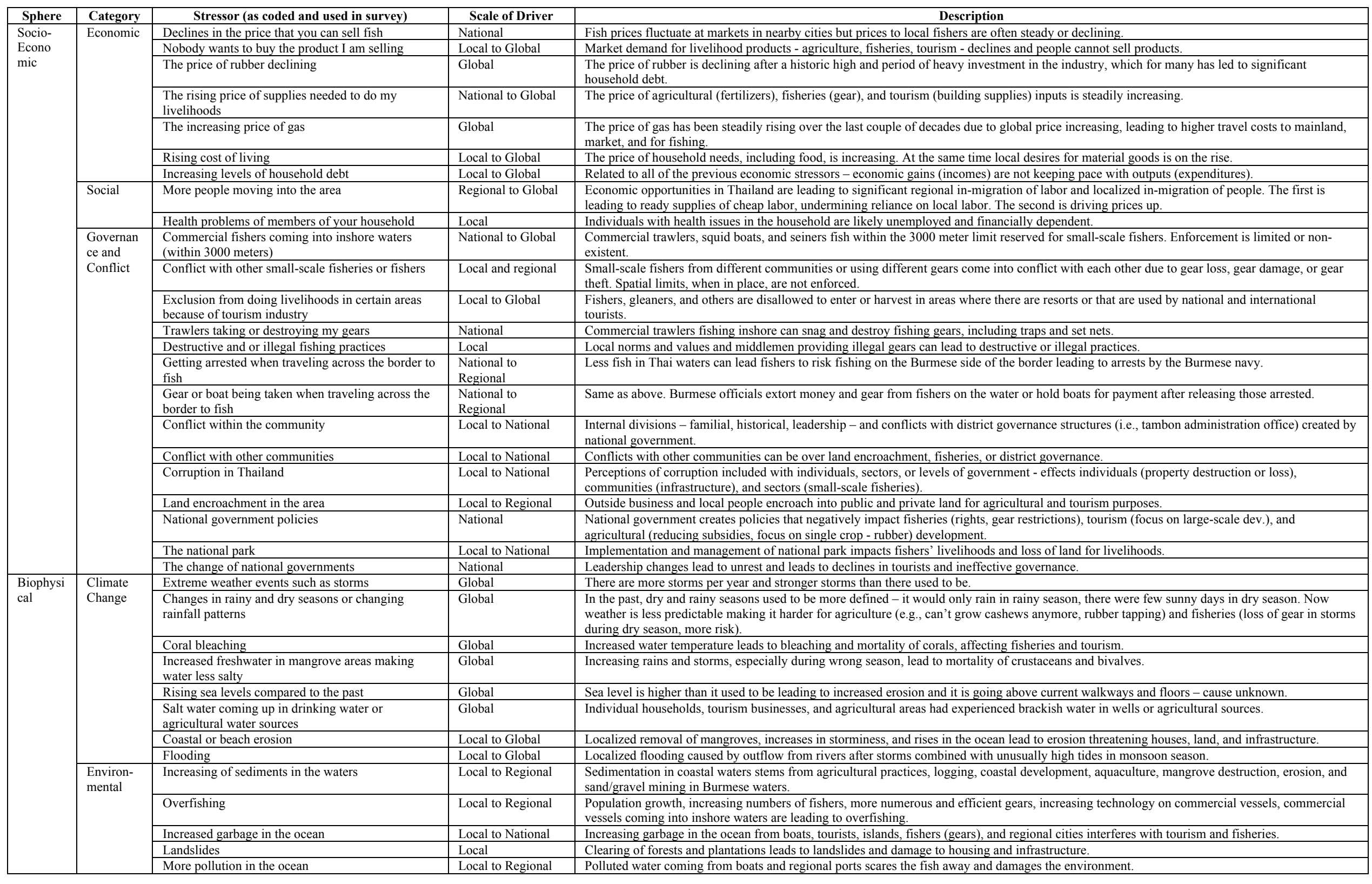




\section{Survey Results: Household and Individual Characteristics}

Initially between $21-34.9 \%$ of households in a community $(n=279)$ were selected to participate but fifteen percent $(n=42)$ of households did not complete the survey due primarily to absence, not wanting to participate, or relocation. In total across the seven communities, 237 households were surveyed, which included between 11 and 64 households per community (18.5-34.9\%) (see Table 1). We present descriptive results here for household (Table 1) and interviewee characteristics (in text) for factors that were considered as potential predictors of perceived stressors (see also Appendix A).

Some characteristics of the interviewees (the individual who completed the household survey) are provided here. Interviewees were predominantly female $(n=140 / 237,59.1 \%)$ and the overall mean age was 42.1 years $(\min =14.0 ; \max =72.0)$. The primary occupation of the interviewees were $24.9 \%$ other (government employees, store owners, informal recycling, vocational, construction), 19.8\% fisheries, $17.7 \%$ subsistence, $14.8 \%$ tourism, $13.5 \%$ agriculture or plantations, and $8.9 \%$ student or unemployed. Almost half (47.7\%) of interviewees had only completed between Year 4-6 of formal education while $17.3 \%$ had finished less than Year 3 and the remainder had completed middle school or higher. On average, interviewees had held 2.3 different occupations in the past 10 years with $60 \%$ of respondents holding 1-2 occupations and 38\% holding 3 or more during this time period. The mean number of years that interviewees lived in the community in all sites was 27.3 years with a community mean minimum of 4.8 years in Baan Moken due to it being a post-tsunami community and a mean maximum of 33.8 years in Baan Koh Panyee. Across all communities, interviewees participated in an average of 0.6 community organizations in the following ways: attend and listen (64.6\%), attend and speak $(34.6 \%)$, active member (40.1\%), member of committee (11.8\%) and elected leader (5.9\%). The majority (78.9\%) of survey participants had learned about climate change from at least one source. Overall, all participants had learned about climate change from an average of 2 different sources - with television (67.9\% of participants), radio (34.2\%), other (22.8\%), friends and family (15.2\%), community leaders $(11.4 \%)$ and newspapers $(11 \%)$ being the most important sources of climate change information.

Households had an average of 4.4 appliances from a list that included clay stove, gas stove, cell phone, radio, television, fridge, computer, and air conditioner. A total of $52.3 \%$ of households indicated that they owned land for livelihood purposes. Household incomes were further analyzed at the community level. Mean annual incomes (Table 3) ranged from \$2,968USD/year in Ban Moken to $\$ 10,068 \mathrm{USD} /$ year in Ban Koh Panyee $(\mathrm{p}<0.001)$. Income (community mean) from fisheries ranged from \$510USD/year to $\$ 2,477$ USD/year. Yet results for the survey question: "household most important livelihood in terms of income", across all the communities, indicated fisheries at $35.4 \%$ ( $\mathrm{min}=6.7 \%$; $\max =81.8 \%$; sig. $\operatorname{diff}=<.001)$, then tourism at $22.8 \%(\min =0 \% ; \max =39.6 \%$; sig. diff. $=<.001)$, then other (i.e., govt. worker, store, recycling, construction) at $19.8 \%$ ( $\min =9.1 \%$; $\max =26.7 \%$; sig. diff. $=<.001)$, then agriculture and plantations at $11.8 \%(\min =0 \% ; \max =38.7 \%$; sig.diff.$=<.001)$. The other households relied on subsistence-based livelihoods (0.8\%), were unemployed (7.2\%), or were not specified (2.1\%). Finally, though economic dependence on fisheries was declining among households subsistence needs remained high with $72 \%$ of households across all communities eating seafood 5 or more nights of the week. 
Table 3 - Household characteristics from survey

\begin{tabular}{|c|c|c|c|c|c|c|c|c|c|}
\hline \multirow{2}{*}{$\begin{array}{c}\text { Comm- } \\
\text { unity } \\
\text { (Baan) }\end{array}$} & \multirow{2}{*}{$\begin{array}{c}\text { Mean } \\
\text { household } \\
\text { income - } \\
\text { Thai baht } \\
\text { (USD*) }\end{array}$} & \multirow{2}{*}{$\begin{array}{c}\text { Mean hh } \\
\text { fisheries } \\
\text { income - } \\
\text { Thai baht } \\
\text { (USD*) }\end{array}$} & \multirow{2}{*}{$\begin{array}{c}\text { \% of hh } \\
\text { eating } \\
\text { seafood }> \\
5 \text { nights } \\
\text { per week }\end{array}$} & \multicolumn{4}{|c|}{$\begin{array}{c}\text { Most important livelihood for income - } \\
\text { \# (\%) of households }\end{array}$} & \multirow{2}{*}{$\begin{array}{c}\text { Land } \\
\text { ownership } \\
\text { for } \\
\text { livelihoods - } \\
\%=Y\end{array}$} & \multirow{2}{*}{$\begin{array}{l}\text { Mean \# of } \\
\text { household } \\
\text { appliances }\end{array}$} \\
\hline & & & & Fishery & Tourism & $\begin{array}{c}\text { Agri- } \\
\text { culture }\end{array}$ & Other & & \\
\hline $\begin{array}{l}\text { Tha Khao } \\
(n=41)\end{array}$ & $\begin{array}{r}237893 \\
(\$ 7,613) \\
\end{array}$ & $\begin{array}{c}36726 \\
(\$ 1175) \\
\end{array}$ & 88 & $4(9.8)$ & $14(34.1)$ & $15(36.6)$ & $4(9.8)$ & 68.3 & 5.2 \\
\hline $\begin{array}{l}\text { Koh Panyee } \\
(\mathrm{n}=53)\end{array}$ & $\begin{array}{c}314611 \\
(\$ 10,068)\end{array}$ & $\begin{array}{r}15943 \\
(\$ 510) \\
\end{array}$ & 93 & $5(9.4)$ & $21(39.6)$ & $0(0.0)$ & $23(43.4)$ & 41.5 & 4.9 \\
\hline $\begin{array}{l}\text { Lions } \\
(\mathrm{n}=15)\end{array}$ & $\begin{array}{r}150781 \\
(\$ 4,824) \\
\end{array}$ & $\begin{array}{r}31120 \\
(\$ 996) \\
\end{array}$ & 47 & $1(6.7)$ & $6(40.0)$ & $1(6.7)$ & $4(26.7)$ & 53.3 & 4.1 \\
\hline $\begin{array}{l}\text { Tapae Yoi } \\
(\mathrm{n}=22)\end{array}$ & $\begin{array}{r}200183 \\
(\$ 6,406)\end{array}$ & $\begin{array}{c}62004 \\
(\$ 1984)\end{array}$ & 45 & $15(68.2)$ & $3(13.6)$ & $0(0.0)$ & $2(9.1)$ & 54.5 & 4.6 \\
\hline $\begin{array}{l}\text { Koh Chang } \\
(\mathrm{n}=31)\end{array}$ & $\begin{array}{r}237955 \\
(\$ 7,615)\end{array}$ & $\begin{array}{r}17290 \\
(\$ 553)\end{array}$ & 58 & $3(9.7)$ & $10(32.3)$ & $12(38.7)$ & $5(16.1)$ & 87.1 & 4.5 \\
\hline $\begin{array}{l}\text { Moken } \\
(\mathrm{n}=11)\end{array}$ & $\begin{array}{c}92750 \\
(\$ 2,968) \\
\end{array}$ & $\begin{array}{c}77401 \\
(\$ 2477) \\
\end{array}$ & 64 & $9(81.8)$ & $0(0.0)$ & $0(0.0)$ & $2(18.2)$ & 36.4 & 2.9 \\
\hline $\begin{array}{l}\text { Koh Sin Hi } \\
(\mathrm{n}=64)\end{array}$ & $\begin{array}{r}107757 \\
(\$ 3,448) \\
\end{array}$ & $\begin{array}{c}57271 \\
(\$ 1833) \\
\end{array}$ & 69 & $47(73.4)$ & $0(0.0)$ & $0(0.0)$ & 7 (10.9) & 35.9 & 3.5 \\
\hline $\begin{array}{l}\text { Totals } \\
(\mathrm{n}=237)\end{array}$ & $\begin{array}{r}204165 \\
(\$ 6,533) \\
\end{array}$ & $\begin{array}{r}38964 \\
(\$ 1247) \\
\end{array}$ & 72 & $84(35.4)$ & $54(22.8)$ & $28(11.8)$ & $47(19.8)$ & 52.3 & 4.4 \\
\hline p-value & $<0.0001 * *$ & $<0.001 * *$ & $<.0001 * *$ & & $<0.0$ & $1 * * *$ & & $<0001^{* *}$ & $<0.001 * *$ \\
\hline
\end{tabular}

Notes: $*$ Conversion rate of $0.032 ; * *$ Test of Sig=ANOVA; $* * *$ Test of Sig. $=\mathrm{Chi}^{2}$

\section{Survey Results: Impacts of Stressors on Households}

The mean scores of the impacts of stressors revealed some interesting results (see Figure 3). First, the mean scores of socio-economic stressors showed great variability (lowest $=1.4$; highest $=4.16$; average $=2.54$ ) but the highest rated stressors were related to economics. Governance and conflict indicators were not as highly rated - remaining within the 1.4 to 3.02 range (average $=2.09$ ). The only governance and conflict stressor rated higher than 3 was "commercial fishers coming into inshore waters". Though it was discussed quite often in the interviews, quantitative results suggest that the national (marine) park - rated at 2.31 - contributes only marginally to overall household vulnerability. Social indicators were rated between 2.37 and 2.83 (average=2.6) - with "health problems of members of your household" being the highest ranked social stressor. Economic stressors received much higher ratings overall with a range of 2.29 to 4.16 (average $=3.43$ ) and 5 out of 7 stressors being rated higher than 3. "Rising cost of living", "The increasing price of gas", and "The rising price of supplies needed to do my livelihoods" were ranked highest at 4.16, 4.05, and 4.02 respectively. Stressors related to market demand - including "Nobody wants to buy the product that I am selling", "Declines in the price that you can sell fish", and "The price of rubber declining" - were rated lower at 3.39, 2.96, and 2.29. "Increasing levels of household debt" was rated at 3.11.

Secondly, biophysical stressors showed less variability (lowest $=1.61$; highest $=3.96$ ) but were rated slightly higher overall (average=2.84). Five of the seven climate change related factors (lowest=2.19; highest=3.96; average=2.84), including "coral bleaching", "coastal or beach erosion", "salt water coming up in drinking water or agricultural water sources", "rising sea levels compared to the past", and "increased freshwater in mangrove areas making water less salty", were rated between 2 and 3. However, "changes in in rainy and dry seasons or changing rainfall patterns" and "extreme weather events such as storms" were rated higher at 3.46 and 3.96 respectively. Other environmental factors were rated between 1.61 and 3.64 (average=2.85). "Increased garbage in the ocean" was rated highest at 3.64 and 
"increasing of sediments in the waters" was rated second at 3.18. "Overfishing" and "more pollution in the ocean" were both rated at 2.91 .

\section{Survey Results: Modeled Impacts of Stressors}

Modeled impacts of community and individual and household characteristics (defined in Appendix A) on perceptions of stressors showed that community as well as individual and household livelihoods were the most significant predictors overall (see Table 4 - Note that the direction of impacts as shown in Table 4 can be understood as follows: An upward arrow indicates a relationship between an increase in the predictor and a corresponding increase in the impact of the stressor; a downward arrow indicates an increase in the predictor corresponds to an decrease in the perceived impact of the stressor.). Otherwise general relationship patterns between household and individual characteristics and perceptions of stressors were somewhat unclear. Community was the strongest predictor for the most stressors (15 stressors with $\mathrm{p}<.01$ and 4 stressors with $\mathrm{p}<.05-.01)$, specifically stressors related to perceived impacts of economic prices, fisheries conflicts, and climatic changes.

The household's most important livelihood by income was a significant predictor for perceptions of many stressors, particularly those stressors directly related to livelihoods (e.g., prices, fisheries conflicts, overfishing). For example, households with a dependence on fisheries-based livelihoods had an increased perceived impact of the price of fish and households with a strong dependence on agriculturebased livelihoods had a higher perceived impact of the price of rubber (results not shown). Households that indicated they were primarily dependent on fisheries-based livelihoods were also more concerned about the price of gas. Households dependent on tourism were more troubled by interest in their product and flooding. The level of household dependence on fisheries for livelihoods (by level of income from fisheries) was significantly related to perceptions of increased impacts from a number of stressors including the price of fish and fisheries-related conflicts as well as extreme weather events and overfishing. 
Vulnerability to Multiple Stressors 14

Figure 3-Bar graph showing mean ratings of the relative impact of all stressors on household livelihoods (Likert scale of 1-5: 1 = no impact, $2=$ very little impact, 3 = medium level of impact, $4=$ high level of impact, $5=$ very high level of impact)

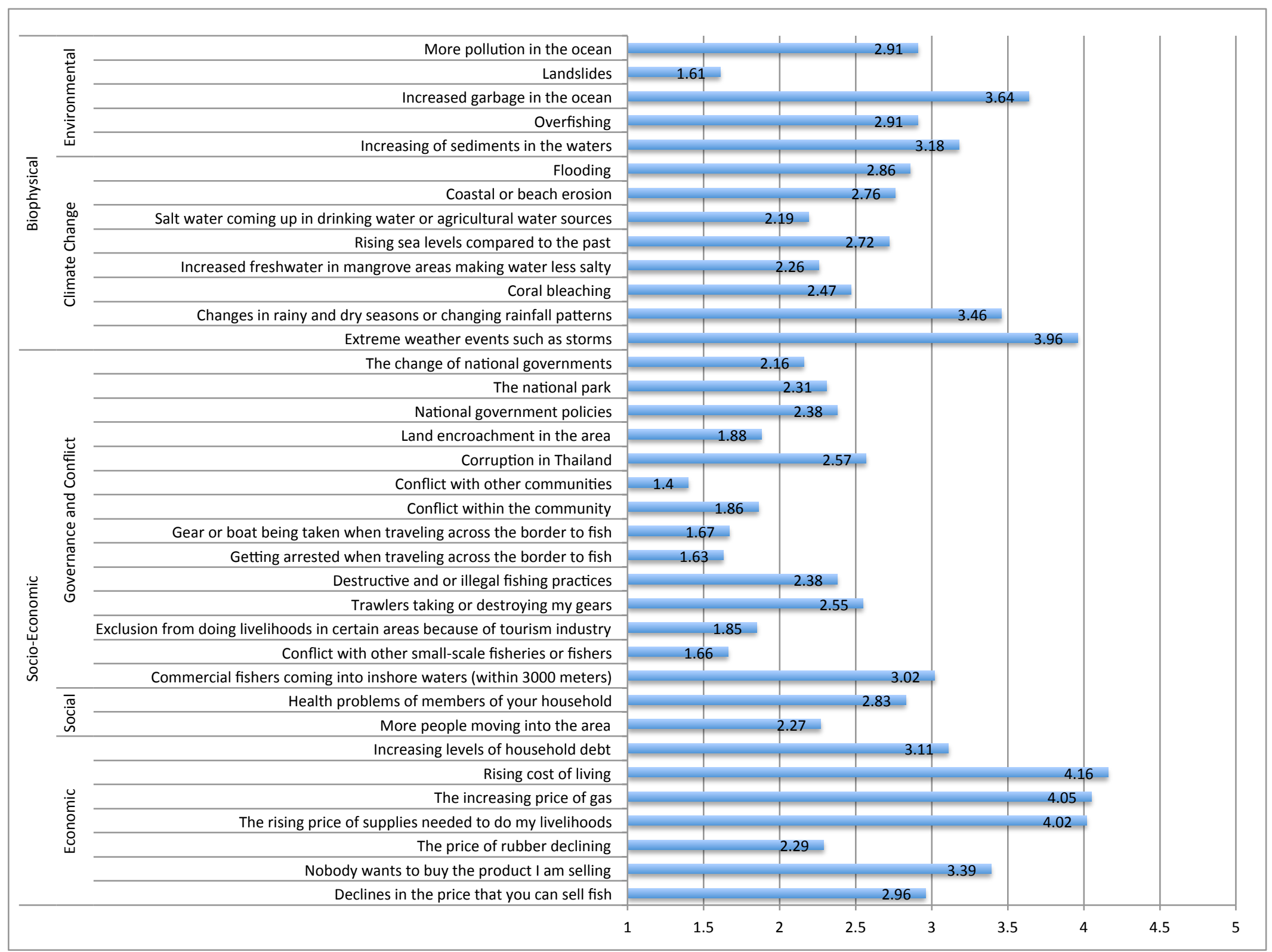


Higher household incomes were related to higher anxiety about interest in products, intracommunity conflict, and overfishing and lower anxiety about several fishing related stressors perhaps reflecting greater resilience of those with higher incomes. Concerns about the price of fish, trawlers, and cross border arrests were lower for those households with more appliances. Yet households with more appliances were often more concerned about conflicts and governance, in-migration, increasing debts, market interest, and prices of rubber. Land ownership for livelihoods led to more concern about government policies, changes in seasons and rainfall, levels of debt, the price of rubber, and commercial fishers and less anxiety about fish prices and health problems.

The primary occupation of the interviewee also influenced the perceptions of many stressors, including increasing concerns about specific livelihood-related stressors. Individuals who identified in fishing-based livelihoods indicated an increased for stressors that were fishing related. Those interviewees with primary livelihoods of subsistence, fisheries, and other were more concerned about extreme weather events than those most dependent on tourism and agriculture and plantations. Interviewees dependent on tourism or who were unemployed were the least anxious about the price of gas. The price of supplies was the highest concern for those with primary livelihoods of other, tourism, and subsistence. Older interviewees were marginally $(\mathrm{p}<.05-.01)$ less worried about in-migration, crossborder fishing, intra-community conflict, changing governments, storms, and salt water in freshwater sources. A number of stressors showed a relationship with gender - women tended to be more concerned about economic costs, the impact of health of their family members, extreme weather events, changing rainfall, flooding, sediments, and garbage whereas men were more concerned about things which related to fishing and their ability to conduct their livelihood. In general, the higher the level of formal education of the interviewee the more concerned they were about prices of rubber, levels of debt, and conflict and corruption and the less concerned they were about the price of fish and cross-border fishing. Interviewees with higher occupational mobility were less worried by a number stressors including landslides, saltwater intrusion, rising sea levels, weather events, land encroachment, and the outcomes of cross-border fishing. Individuals with less mobility - i.e., those who had lived in the community longer were more anxious about in-migration, the cost of living, rising debts, the price of rubber, the national park, and market interest. Increasing levels of involvement in community organizations (social capital) was related to higher scores for coastal or beach erosion and saltwater intrusion as well as a number (7) of factors related to governance and conflict. Finally, the number of sources from which interviewees had learned about climate change was related to increased concern about coral bleaching but did not influence levels of concern about other climate change related stressors. 
Vulnerability to Multiple Stressors 16

Table 4 - Modeled impacts of community, individual and household characteristics on perceptions of stressors, model significances

\begin{tabular}{|c|c|c|c|c|c|c|c|c|c|c|c|c|c|c|c|c|}
\hline \multirow[t]{2}{*}{ Sphere } & \multirow[t]{2}{*}{ Category } & \multirow{2}{*}{$\begin{array}{r}\text { Individual and Household } \\
\text { Characteristics }\end{array}$} & \multirow[b]{2}{*}{ 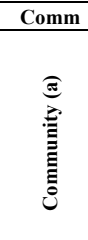 } & \multicolumn{5}{|c|}{ Household Characteristics } & \multicolumn{8}{|c|}{ Individual Characteristics } \\
\hline & & & & 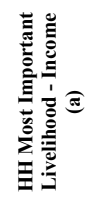 & 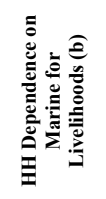 & $\begin{array}{l}\widehat{\varrho} \\
\stackrel{\Xi}{\Xi} \\
\stackrel{\Xi}{\Xi} \\
\Xi\end{array}$ & 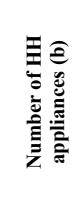 & 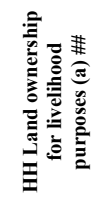 & 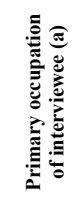 & 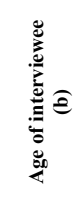 & 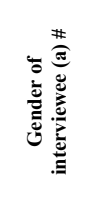 & 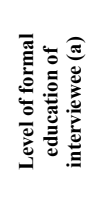 & 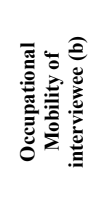 & 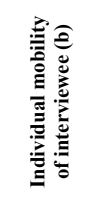 & 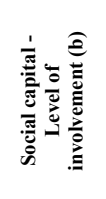 & 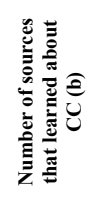 \\
\hline \multirow{23}{*}{$\begin{array}{l}\text { Socio- } \\
\text { Econo } \\
\text { mic }\end{array}$} & \multirow[t]{7}{*}{ Economic } & Declines in the price that you can sell fish & $* * * *$ & ***** & $* * * * \uparrow$ & $* * \downarrow$ & $* * * * \downarrow$ & $* * \mathrm{Y}=\downarrow$ & $* * * *$ & & & $* * \downarrow$ & & & & \\
\hline & & Nobody wants to buy the product I am selling & ***** & * & & ${ }^{*} \uparrow$ & $* * \uparrow$ & & ${ }^{* * * *}$ & & & & & ${ }^{*} \uparrow$ & & \\
\hline & & The price of rubber declining & $* * * *$ & $* * * *$ & & & $* * * * \uparrow$ & $\begin{array}{l}* * * * \\
\mathrm{Y}=\uparrow\end{array}$ & ${ }^{* * * * *}$ & & & $* \uparrow$ & & $* * * \uparrow$ & & $* \uparrow$ \\
\hline & & $\begin{array}{l}\text { The rising price of supplies needed to do my } \\
\text { livelihoods }\end{array}$ & & & & & & ${ }^{* *} \mathrm{Y}=\uparrow$ & * & & ${ }^{*} \mathrm{M}=\downarrow$ & & & & & ${ }^{* *} \uparrow$ \\
\hline & & The increasing price of gas & & * & & & & & ** & & ${ }^{* *} \mathrm{M}=\downarrow$ & & & & & \\
\hline & & Rising cost of living & & & & & & & & & & & & $* * \uparrow$ & & \\
\hline & & Increasing levels of household debt & $*$ & & & & $* \uparrow$ & ${ }^{*} \mathrm{Y}=\boldsymbol{\uparrow}$ & & & & $* \uparrow$ & & $* \uparrow$ & & $* \uparrow$ \\
\hline & \multirow[t]{2}{*}{ Social } & More people moving into the area & ** & & & & $* \uparrow$ & & & $* \downarrow$ & & $* \uparrow$ & & $* \uparrow$ & & $* * * * \uparrow$ \\
\hline & & Health problems of members of your household & & & & & & ${ }^{*} \mathrm{Y}=\downarrow$ & ${ }^{*}$ & & $* \mathrm{M}=\downarrow$ & & & & & \\
\hline & \multirow{14}{*}{$\begin{array}{l}\text { Governan } \\
\text { ce and } \\
\text { Conflict }\end{array}$} & $\begin{array}{l}\text { Commercial fishers coming into inshore waters } \\
\text { (within } 3000 \text { meters) }\end{array}$ & ***** & ** & **** & & & ${ }^{*} \mathrm{Y}=\boldsymbol{\uparrow}$ & *** & & & & & & $* * \uparrow$ & \\
\hline & & Conflict with other small-scale fisheries or fishers & & & ${ }^{* *} \uparrow$ & & & & & & & & & & & \\
\hline & & $\begin{array}{l}\text { Exclusion from doing livelihoods in certain areas } \\
\text { because of tourism industry }\end{array}$ & & & & & & & & & ${ }^{*} \mathrm{M}=\boldsymbol{\uparrow}$ & & & & $* \uparrow$ & $* \uparrow$ \\
\hline & & Trawlers taking or destroying my gears & ${ }^{* * * *}$ & ***** & ***^ & $* \downarrow$ & $* * \downarrow$ & & ${ }^{* * * * *}$ & & ${ }^{*} \mathrm{M}=\uparrow$ & & & & & \\
\hline & & Destructive and or illegal fishing practices & & & ${ }^{* * \uparrow} \uparrow$ & $* \downarrow$ & & & & & & & & & ${ }^{* * \uparrow} \uparrow$ & \\
\hline & & $\begin{array}{l}\text { Getting arrested when traveling across the border to } \\
\text { fish }\end{array}$ & ***** & ***** & ${ }^{* * * *} \uparrow$ & & $* * \downarrow$ & & $* * * *$ & $* \downarrow$ & & **ף & $* \downarrow$ & & & \\
\hline & & $\begin{array}{l}\text { Gear or boat being taken when traveling across the } \\
\text { border to fish }\end{array}$ & ***** & *** & $* * * \uparrow$ & & & & * & $* \downarrow$ & & & $* \downarrow$ & & & \\
\hline & & Conflict within the community & & & & $* \uparrow$ & $* \uparrow$ & & & $* \downarrow$ & & ${ }^{* * * *} \uparrow$ & & & $* \uparrow$ & ${ }^{* * *} \uparrow$ \\
\hline & & Conflict with other communities & & & & & & & & & & & & & & $* \downarrow$ \\
\hline & & Corruption in Thailand & & & & & $* \uparrow$ & & & & & ${ }^{*} \uparrow$ & & & & ${ }^{* * *} \uparrow$ \\
\hline & & Land encroachment in the area & & & & & & & & & & $* \uparrow$ & $* * \downarrow$ & & $* \uparrow$ & ${ }^{*} \uparrow$ \\
\hline & & National government policies & & & & & $* * \uparrow$ & $* * \mathrm{Y}=\boldsymbol{\uparrow}$ & & & & ${ }^{* *} \uparrow$ & & & & $* * \uparrow$ \\
\hline & & The national park & ${ }^{* * * *}$ & & & & $* \uparrow$ & & & & & ${ }^{*} \rightarrow$ & & $* \uparrow$ & ${ }^{* * \uparrow} \uparrow$ & $* \uparrow$ \\
\hline & & The change of national governments & & & & & $* * \uparrow$ & & & $* \downarrow$ & & & & & ${ }^{* \uparrow} \uparrow$ & \\
\hline \multirow{13}{*}{$\begin{array}{l}\text { Biophysi } \\
\text { cal }\end{array}$} & \multirow{8}{*}{$\begin{array}{l}\text { Climate } \\
\text { Change }\end{array}$} & Extreme weather events such as storms & " & ${ }^{* * * *}$ & ${ }^{* * *} \uparrow$ & & & & * & $* \downarrow$ & $* \mathrm{M}=\downarrow$ & & $* \downarrow$ & & & \\
\hline & & $\begin{array}{l}\text { Changes in rainy and dry seasons or changing } \\
\text { rainfall patterns }\end{array}$ & & & & & & ${ }^{*} \mathrm{Y}=\uparrow$ & & & ${ }^{* *} \mathrm{M}=\downarrow$ & & & & & \\
\hline & & Coral bleaching & ** & & & & & & & & & & & & & $* * \uparrow$ \\
\hline & & $\begin{array}{l}\text { Increased freshwater in mangrove areas making } \\
\text { water less salty }\end{array}$ & ${ }^{*}$ & * & ${ }^{*} \uparrow$ & $* \downarrow$ & & & * & $* \downarrow$ & & & & & & \\
\hline & & Rising sea levels compared to the past & **** & & & & & & & & & & $* \downarrow$ & & & \\
\hline & & $\begin{array}{l}\text { Salt water coming up in drinking water or } \\
\text { agricultural water sources }\end{array}$ & ${ }^{* * * *}$ & * & & & & & * & $* \downarrow$ & & & $* \downarrow$ & & $*^{* \uparrow}$ & \\
\hline & & Coastal or beach erosion & *** & & & & & & & & & & & & $* \uparrow$ & \\
\hline & & Flooding & * & $* * *$ & & & & & ** & & ${ }^{*} \mathrm{M}=\downarrow$ & & & & & \\
\hline & \multirow{5}{*}{$\begin{array}{l}\text { Environ- } \\
\text { mental }\end{array}$} & Increasing of sediments in the waters & & & ${ }^{*} \uparrow$ & & & & * & & ${ }^{*} \mathrm{M}=\downarrow$ & & & & & \\
\hline & & Overfishing & **** & ***** & **** & $* * \uparrow$ & & & ${ }^{* * * * *}$ & & & & & & & \\
\hline & & Increased garbage in the ocean & & & & & & & & & ${ }^{* * *} \mathrm{M}=\downarrow$ & & & & & \\
\hline & & Landslides & ** & & & & & & & & & & $* \downarrow$ & & & \\
\hline & & More pollution in the ocean & & * & ${ }^{*} \uparrow$ & & & & & & & & & & & \\
\hline
\end{tabular}




\section{Discussion}

The qualitative results from interviews showed the multiple stressors that communities are experiencing. The 36 stressors that emerged from the interviews were categorized as socio-economic stressors (i.e., social, governance and conflict, economic) and biophysical (i.e., climate change and other environmental). The stressors identified in this case study are not unique to this locale (Zou \& Wei, 2010). The rating of these stressors through a household survey demonstrated that certain stressors were perceived to have a higher impact - particularly economic stressors and some climatic and environmental stressors - than others. These results suggest that both some climate change stressors extreme weather events and changes in weather patterns - and economic globalization - through shifting commodity prices and market demands - are being felt profoundly by coastal communities in Thailand, which is a significant concern as both processes are likely to continue and to accelerate (O'Brien \& Leichenko, 2000). Thus these results could be seen as confirmatory of a "Double Exposure" scenario (i.e., Leichenko \& O'Brien, 2008); yet, clearly the wider array of stressors that emerged from interviews suggest that "multiple exposures" is a better term. Our results showed that economic considerations were scored higher than climate change stressors, which differs from several other studies from very different contexts that have rated climate change as the most impactful stressor (Bunce, Rosendo, et al., 2010; Mubaya et al., 2012). The high scores associated with rising costs and debts suggest that in Thailand, despite increasing economic opportunities, incomes in coastal communities may not be keeping pace with the rising costs associated with livelihoods or households. Similarly, Tuler et al (2008, p.177) comment that "the cost of fuel, insurance, gear, and bait have all gone up, while the price for fish has not" for US fishers. Additionally, increasing household costs may be as related to increasing local desires and expectations as to increasing costs at both the local (e.g., water, food) and global (e.g., gas, food, supplies). Marine protected areas and resource conservation measures, other studies have shown, can add increased stress to local communities (Bunce, Brown, et al., 2010; Bunce, Rosendo, et al., 2010) whereas in this study MPAs were perceived to have a fairly low amount of stress. This might, however, be due to the limited enforcement of MPA regulations in the Thai context. Finally, it was unexpected that "overfishing" did not score higher, perhaps this is because major fisheries declines are already a distant artifact (Panjarat, 2008).

Modeled impacts of community, individual characteristics, and household characteristics showed that community and livelihoods had the most consistent impacts on perceptions of stressors. It is not surprising that there were significant differences across communities since they were chosen for heterogeneity; however, even while choosing communities we were struck by the vast differences between communities that were only 10 kilometres apart so this difference would have likely persisted with a more randomized sample. Livelihoods groups (across all communities) had different perceptions which were often related to particular stressors that would impact that livelihood directly - for example, local small-scale fishers were more concerned about commercial fishers whereas tourism operators were more concerned about flooding - while all groups were equally anxious about stressors such as the cost of living or the cost of livelihood supplies. These results suggest that greater diversity in livelihoods, rather than reliance on a single livelihood, would reduce vulnerability to individual stressors and increase overall adaptability. We expected to see more clearly differentiated responses to stressors by specific groups other than households or livelihoods as suggested by several authors (Brklacich et al., 2010; O’Brien \& Leichenko, 2003) - for example, genders or socio-economic groups - however, these differences by group were not particularly distinct. We were also surprised that increasing involvement in organizations (i.e., social capital) was related to increased concern about conflicts and governance but that it did not lead to significant differences in perceptions across all economic stressors and most biophysical stressors. This may also be because formal organizations are responsible for addressing 
conflicts or governance issues whereas informal social organization and communication plays a more significant role in leading to collective or shared understandings of economic and environmental woes.

Various authors have suggested that multiple stressors may further increase vulnerability and undermine the adaptive capacity of households and communities faced with the impacts of climate change. Since it was beyond the scope of this research to examine how the various stressors interact, we will extrapolate on these findings to explore how the interaction between stressors influences the ability of households and communities to adapt. First, economic difficulties or stressors may lead individuals, households or communities to abandon or ignore environmental risk mitigation behaviors (see also Eakin, 2005). In particular for fishers, climate change affects them both on land and at sea and may exacerbate dangers faced at sea (Tuler et al., 2008). Economic stress may lead to decisions - such as making shortcuts on boats, housing, or infrastructure or risking life, injury, or loss of property through continuing to work in hazardous conditions or attempting to rescue valuable gear (nets or traps) from impending storms - that may make individuals and households more vulnerable to environmental stresses over the longer term. Climate change stressors that households rated as having a high level of impact - i.e., storm events and changing seasons - tend to be more random and less predictable making it harder to plan for these events. For households that are already impoverished or vulnerable, a sporadic climate related event that impacts a house or a boat, leads to the loss of fishing gear, or causes injury would likely lead to increasing household debt, impoverishment, or overall vulnerability. Rising debts and costs may also constrain people's abilities to take actions even when based on knowledge of impending climatic events - for example through radio forecasts.

Secondly, the other stressors identified during this research that were rated lower in the surveys - i.e, governance and conflict, social, and other environmental - would also increase vulnerability and decrease adaptive capacity. Health issues or persistent conflicts within a community would add to the stress experienced by households. Pollution, sediments, and garbage challenge the health and productivity of ecosystems and thus the viability of fisheries and tourism livelihoods. Many interviewees also discussed how the post-tsunami reconstruction efforts were rife with corruption or how even smaller infrastructure projects did not get completed due to corruption. Corruption has major implications for adaptation policy and projects, particularly where large sums of money from outside donors or international transfer payments are concerned. Some of the stressors that were less highly rated (quantitatively) in the survey may also be more qualitatively important or impactful. For example, corruption or commercial boats fishing in areas reserved for small-scale fishers are highly emotive topics that lead to a sense of injustice or anger whereas economics and climate change may be more emotionally distant. These emotive responses may influence what communities (and higher level governments) discuss and plan for, which may undermine their ability to adapt to less blameworthy but more quantitatively important stressors. Economic stressors may also be ranked higher because financial concerns are a daily reality that impinges directly on a household's ability to purchase daily needs or pursue livelihoods rather than a sporadic climatic shock such as a severe storm or creeping environmental trends such as erosion or fisheries declines.

Third, economic stressors combined with biophysical (environment and climate change) stressors may be leading to significant declines in quality of individual and community life particularly for more vulnerable households and communities with less options. Qualitative results support this assertion. For example, many interviewees commented that the rising price of living means that people need to work harder and longer than they used to make ends meet. Increasing costs combined with environmental declines (e.g., fisheries) and climate stressors have led many fishers to fish longer or to engage in additional livelihoods. Observed impacts of these changes included more hours spent working, decreasing free time, less sharing within the community, and declines in voluntarism and civic engagement (unpublished data). Finally, the impact of climatic and environmental stressors on marine ecosystem services likely has a significant influence on individual well-being (e.g., physical, mental 
health, inspiration, identity; see Russell et al., 2013) and community economies and social functioning (see Bennett \& Dearden, 2013a).

There are a number of important implications of the results and discussion presented in this paper for future research, policy and practice. Most importantly, the presence of multiple stressors needs to be taken into account in the planning of adaptation policy and programs and for the design and prioritization of adaptive strategies to reduce overall vulnerability. This requires a nuanced qualitative and quantitative understanding of the types, severity, and impacts of these stressors as they are experienced by people in different communities, groups, industries, and regions. Thus, we reiterate calls for increased empirical studies that focus on double and multiple exposures with an additional focus on the perceived and experienced interactions between the stressors - and between social and ecological systems. The measurement of perceptions, as in this study, of multiple stressors may be a useful proxy when doing rapid rural assessments or could be done in conjunction with an array of other technical or participatory assessments. We also recommend the development of comprehensive vulnerability frameworks that bring together previous research on the many stressors that communities are experiencing in many different environments to act as checklists for future qualitative or quantitative explorations or for practical use in vulnerability, adaptive capacity, or adaptation projects. Three additional areas for research are: 1) to examine why some stressors are rated higher than others from the perception of local people, 2) to further clarify the role of various social, cultural, institutional, economic, and political factors in mediating the impact of and adapting to multiple (rather than singular) stressors and 3) to connect the stressors, as they are felt by local communities, more directly to the multi-scalar environmental, economic, and socio-political drivers that are causing them.

\section{Conclusion}

This paper offers a mixed-methods and perceptions-based exploration of the nature, magnitude, and differential impacts of the multiple socio-economic and biophysical stressors being experienced by coastal communities within a particular context. It presents 36 socio-economic (i.e., economic, social, governance and conflict) and biophysical (i.e., climate change and other environmental) stressors that are being experienced by coastal communities on the Andaman coast of Thailand and shows that economic and some climate change stressors - extreme weather events and changes in rainfall patterns and seasons - are perceived to be more impactful than other stressors. The paper also examines the relationships between community and various individual and household characteristics and the perceived level of impacts of the stressors. Overall, community and livelihoods had the most differentiated impacts on perceptions of stressors but few other prominent patterns emerged.

In conclusion, we posit that the presence of stressors occurring at multiple scales and the overall prevalence of stressors that are driven by changes occurring at higher scales, that are less predictable, and that shift the locus of control away from vulnerable groups affirms the need for programs of mitigation and adaptation that are occurring at multiple scales simultaneously (see also Brklacich et al., 2010; Ostrom, 2010). We also concur with Eakin (2005, p 1923) who states that "[t]he dominance of economic uncertainty over environmental risk in households' decision-making implies a continued role for government [and other external organizations] intervention in climate change adaptation". Indeed, there are many important places for outside programs, both from civil society and government organizations, that focus on reducing vulnerability and building adaptive capacity through contributing funding, strengthening national policy on adaptation and rural development, improving infrastructure, providing climate change education, facilitating contextualized adaptation programs, and diversifying livelihoods (see Bennett, Dearden, Murray \& Kadfak, in press). Additionally, the relative importance given to climate change stressors in this analysis suggests that adaptation to climate change (in conjunction with the multiple stressors facing communities) needs to be planned for now not at some distant point in the future. The widespread concerns about biophysical stressors made apparent in this 
article could be leveraged to promote an increased focus on adaptation in policy and practice. Finally, these results point to community and livelihoods (by sector) rather than households or individuals as the most suitable places to focus when planning adaptive responses.

Acknowledgements: The results presented in this article are one aspect of the work of Project IMPAACT (http://projectimpaact.asia) - a project of the Marine Protected Areas Research Group, Department of Geography, University of Victoria, Canada. Financial support for this project came from the Social Science and Human Research Council of Canada and the Bay of Bengal Large Marine Ecosystem Project. At the time of writing, the principle author of this article was a Trudeau Scholar, a SSHRC Scholar, a Fellow of the Centre for Global Studies, and an Associate Fellow of the Centre for Co-operative and Community-Based Economy. We would like to recognize our Thai partners - the Department of National Parks, Phuket Marine Biological Centre, and Prince of Songkla University - and the invaluable contribution of three research assistants - Piyapat Nakornchai (Por), Alin Kadfak, and Jutathorn Pravattiyagul (Aice). The map was created by Ole Heggen.

\section{References}

Adger, W. N., 2003. Social aspects of adaptive capacity. Climate Change, Adaptive Capacity and Development, J. B. Smith, R. J. T. Klein, and S. Huq (eds.). Imperial College Press, London, UK. 29-49.

Adger, W. N., 2006. Vulnerability. Global Environmental Change, 16(3): 268-281.

Adger, W. N., and Mick, P., 2001 Living with Environmental Change: Social Vulnerability, Adaptation and Resilience in Vietnam. Routledge, London, UK.

Andaman Discoveries, 2012. Ban Lion village - Community based tourism in Thailand. http://www.andamandiscoveries.com/village-koh-phratong-thailand/. [Accessed on 31 October 2012].

Arunotai, N., 2006. Moken traditional knowledge: An unrecognised form of natural resources management and conservation. International Social Science Journal, 58(187): 139-150.

Baker, C., and Phongpaichit, P., 2009. A History of Thailand. Cambridge University Press, Cambridge, UK.

Barnett, J., Matthew, R. A., O’Brien, K. L., 2010. Human security, vulnerability, and global environmental change. Global Environmental Change and Human Security, R. A. Matthew, J. Barnett, B. McDonald, and K. L. O'Brien (eds.). The MIT Press, Cambridge, MA. 3-32.

Bennett, N. 2013. The capacity to adapt, conserve and thrive?: Marine protected area communities and social-ecological change in coastal Thailand. Unpublished dissertation, University of Victoria, Canada.

Bennett, N. J., Dearden, P., 2013a. A picture of change: Using photovoice to explore social and environmental change in coastal communities on the Andaman Coast of Thailand. Local Environment: The International Journal of Justice and Sustainability, [online]. URL: http://www.tandfonline.com/doi/abs/10.1080/13549839.2012.748733

Bennett, N. J., Dearden, P., 2013b. Why local people do not support conservation: Community perceptions of marine protected area livelihood impacts, governance and management in Thailand. Marine Policy, [online]. URL:

http://www.sciencedirect.com/science/article/pii/S0308597X13001711

Bennett, N. J., Dearden, P., Murray, G., Kadfak, A., in press. The capacity to adapt?: Communities in a changing climate, environment, and economy on the northern Andaman Coast of Thailand. Ecology and Society, in press. 
Blythe, J., 2013. Dynamics of fishers' responses to social-ecological change in coastal Mozambique: A resilience perspective. Unpublished dissertation, University of Victoria, Canada.

BOBLME, 2010. Transboundary Diagnostic Analysis - Volume 1: Issues, Proximate, and Root Causes. Bay of Bengal Large Marine Ecosystem Project, Phuket, Thailand.

Brierley, A. S., and Kingsford, M. J., 2009. Impacts of climate change on marine organisms and ecosystems. Current Biology, 19(14): R602-R614.

Brklacich M., Chazan M., and Bohle H.-G., 2010. Human security, vulnerability, and global environmental change. Global Environmental Change and Human Security, R. A. Matthew, J. Barnett, B. McDonald, and K. L. O'Brien (eds.). The MIT Press, Cambridge, MA. 35-51.

Bunce, M., Brown, K., and Rosendo, S., 2010. Policy misfits, climate change and cross-scale vulnerability in coastal Africa: How development projects undermine resilience. Environmental Science \& Policy, 13(6): 485-497.

Bunce, M., Rosendo, S., and Brown, K., 2010. Perceptions of climate change, multiple stressors and livelihoods on marginal African coasts. Environment, Development and Sustainability, 12(3): 407440.

Chambers, R. 1995. Poverty and livelihoods: Whose reality counts?. Environment and Urbanization, 7(1): 173-204.

Chambers, R., 1984. Rural Development: Putting the Last First. Longman, London, UK.

Eakin, H., 2005. Institutional change, climate risk, and rural vulnerability: Cases from central Mexico. World Development. 33(11): 1923-1938.

Ensor, J., and Berger, R., 2009. Understanding Climate Change Adaptation: Lessons from CommunityBased Approaches. Practical Action Publishing, Rugby, UK

Füssel, H.-M., 2007. Vulnerability: A generally applicable conceptual framework for climate change research. Global Environmental Change, 17(2): 155-167.

Hjerpe, M., and Glaas, E., 2012. Evolving local climate adaptation strategies: Incorporating influences of socio-economic stress. Mitigation and Adaptation Strategies for Global Change, 17(5): 471-486.

Hoegh-Guldberg, O., and Bruno, J. F., 2010. The impact of climate change on the world's marine ecosystems. Science, 328(5985): $1523-1528$.

Juntaroshte, K., 2005. Country Report for BOBLME Programme: Thailand. Bay of Bengal Large Marine Ecosystem Programme, Phuket, Thailand.

Kelly, P. M., and Adger W. N., 2000. Theory and practice in assessing vulnerability to climate change and facilitating adaptation. Climatic Change, 47(4): 325-352.

Klein R. J. T., and Patt A. G., 2012. Assessing Vulnerability to Global Environmental Change: Making Research Useful for Adaptation Decision Making and Policy. Earthscan, London, UK

Lebel, L., Khrutmuang, S., and Manuta, J., 2006. Tales from the margins: Small fishers in post-tsunami Thailand. Disaster Prevention and Management, 15(1): 124-134.

Leichenko, R.M., and O'Brien, K., 2008. Environmental Change and Globalization: Double Exposures. Oxford University Press, Oxford, UK.

Leichenko, R. M., and O'Brien, K. L., 2002. The dynamics of rural vulnerability to global change: The case of southern Africa. Mitigation and Adaptation Strategies for Global Change, 7(1): 1-18.

Leinbach, T. R., and Ulack, R., 2000. Southeast Asia: Diversity and Development. Prentice Hall: Upper Saddle River, NJ.

Marshall, N. A., Marshall, P. A., Tamelander, J., Obura, D., Malleret-King, D., and Cinner, J. E., 2010. A Framework for Social Adaptation to Climate Change: Sustaining Tropical Coastal Communitites and Industries. IUCN, Gland, Switzerland.

McCarthy, J. J, and IPCC, 2001. Climate Change 2001: Impacts, Adaptation, and Vulnerability. Cambridge University Press, New York, NY.

McClanahan, T. R., and Cinner, J., 2011. Adapting to a Changing Environment: Confronting the Consequences of Climate Change. Oxford University Press, Oxford, UK. 
McCubbin, S. G., 2013. Vulnerability to climate change in the context of multiple stressors: The case of Funafuti, Tuvalu. Unpublished Master's Thesis, University of Guelph, Guelph, ON.

Moerlein, K. J., and Carothers, C., 2012. Total environment of change: Impacts of climate change and social transitions on subsistence fisheries in Northwest Alaska. Ecology and Society, 17(1), online.

Mubaya, C. P., Njuki, J., Mutsvangwa, E. P., Mugabe, F. T., and Nanja, D., 2012. Climate variability and change or multiple stressors? Farmer perceptions regarding threats to livelihoods in Zimbabwe and Zambia. Journal of Environmental Management, 102: 9-17.

O’Brien, K. L., Leichenko, R., Kelkar, U., Venema, H., Aandahl, G., Tompkins, H., ... West, J., 2004. Mapping vulnerability to multiple stressors: Climate change and globalization in India. Global Environmental Change, 14(4): 303-313.

O'Brien, K. L., and Leichenko, R. M., 2000. Double exposure: Assessing the impacts of climate change within the context of economic globalization. Global Environmental Change, 10(3): 221-232.

O'Brien, K. L., and Leichenko R. M., 2003. Winners and losers in the context of global change. Annals of the Association of American Geographers, 93(1): 89-103.

Ommer, R. E., and Team. 2007. Coasts under stress: Restructuring and social-ecological health. McGill-Queen's Press, Montreal, QC.

Ostrom, E., 2010. A multi-scale approach to coping with climate change and other collective action problems. Solutions Journal, 1(2): 27-36.

Paavola, J., 2008. Livelihoods, vulnerability and adaptation to climate change in Morogoro, Tanzania. Environmental Science and Policy, 11(7): 642-654.

Panjarat, S., 2008. Sustainable Fisheries in the Andaman Sea Coast of Thailand, Division for Ocean Affairs and the Law of the Sea, Office of Legal Affairs, The United Nations, New York, NY.

Parry, M. L., and IPCC, 2007. Climate Change 2007: Impacts, Adaptation and Vulnerability Contribution of Working Group II to the fourth assessment report of the Intergovernmental Panel on Climate Change. Cambridge University Press, Cambridge, UK.

Perry, R. I., Ommer, R. E., Sumaila, R. U., Allison, E., Barange, M., Hamilton, L., ... Jarre, A., 2010. Interactions between changes in marine ecosystems and human communities. Marine Ecosystems and Global Change, M. Barange, J. Field, R. Harris, E. Hofmann, R. I. Perry, and F. Werner (eds). Oxford University Press, Oxford, UK. 221-252.

Perry, R. I., Ommer, R. E., Barange, M., Jentoft, S., Neis, B., and Sumaila, U. R., 2011. Marine socialecological responses to environmental change and the impacts of globalization. Fish and Fisheries, 12(4): 427-450.

Phongsuwan, N., 2011. Preliminary Report of the Effect of Coral Bleaching in 2010. Phuket Marine Biological Research Centre, Phuket, Thailand.

Reid, P., and Vogel, C., 2006. Living and responding to multiple stressors in South Africa—Glimpses from KwaZulu-Natal. Global Environmental Change, 16(2): 195-206.

Rigg, J., 1995. Counting the Costs: Economic Growth and Environmental Change in Thailand. Institute of Southeast Asian Studies, Singapore.

Russell, R., Guerry, A. D., Balvanera, P., Gould, R. K., Basurto, X., Chan, K. M. A., ... Tam, J., 2013. Humans and nature: How knowing and experiencing nature affect well-being. Annual Review of Environment and Resources, 38(1): 473-502.

Silva, J. A., Eriksen, S., and Ombe, Z. A., 2010. Double exposure in Mozambique's Limpopo River Basin. Geographical Journal, 176(1): 6-24.

START, 2010. Preparation of Climate Change Scenarios for Climate Change Impact Assessment in Thailand. Southeast Asia START Regional Centre, Bangkok, Thailand.

Tuler, S., Agyeman, J., da Silva, P. P., LoRusso, K. R., and Kay, R., 2008. Assessing vulnerabilities: Integrating information about driving forces that affect risks and resilience in fishing communities. Human Ecology Review, 15(2): 171-184. 
Vulnerability to Multiple Stressors 23

Turner, B. L, et al., 2003. A framework for vulnerability analysis in sustainability science. PNAS, 100(14): 8074-8079.

UNDP, 2005. Thailand Millennium Development Goals Report 2004. Office of the National Economic and Social Development Board, Bangkok, Thailand.

http://www.th.undp.org/content/dam/thailand/docs/Thailand\%20MDG2004.pdf. [Accessed on 14 Dec 2012].

UNESCO, 2007. Bridging the Gap Between the Rights and Needs of Indigenous Communities and the Management of Protected Areas: Case Studies from Thailand. UNESCO, Bangkok, Thailand.

Unnikrishnan, A. S., and Shankar, D., 2007. Are sea-level-rise trends along the coasts of the north Indian Ocean consistent with global estimates? Global Planetary Change, 57(3-4): 301-307.

USAID, 2009. Adapting to Coastal Climate Change: A Guidebook for Development Planners. USAID, Washington, DC.

Vogel, C., 1998. Vulnerability and global environmental change. LUCC Newsletter, 3: 15-19.

Wongbusarakum, S., and Loper, C., 2011. Indicators to assess community - level social vulnerability to climate change: An addendum to SocMon and SEM - Pasifika regional socioeconomic monitoring guideline. CRISP and IUCN, Gland, Switzerland.

World Bank, 2012. Thailand - data. The world bank - Working for a world free of poverty. http://data.worldbank.org/country/thailand?display=default. [Accessed on 8 Nov 2012]

World Bank, 2006. Thailand environment monitor 2006: Marine and coastal resources. World Bank, Washington, DC.

World Heritage Nomination Document, 2010. Draft Nomination Document of the Andaman Bioregion of Thailand for UNESCO World Heritage Nomination. Ministry of Natural Resources and Environment, Bangkok, Thailand.

Zou, L.-L., and Wei Y.-M., 2010. Driving factors for social vulnerability to coastal hazards in Southeast Asia: Results from the meta-analysis. Natural Hazards, 54(3): 901-929. 
Vulnerability to Multiple Stressors 24

Appendix A-Details of survey questions and analysis used to calculate interviewee and household (hh) characteristics

\begin{tabular}{|c|c|}
\hline $\begin{array}{l}\text { Individual or } \\
\text { Household (HH) } \\
\text { Characteristic }\end{array}$ & Survey Question and Analysis \\
\hline $\begin{array}{l}\text { HH Most Important } \\
\text { Livelihood* - Income }\end{array}$ & $\begin{array}{l}\text { Survey question: "What is the household's most important livelihood in } \\
\text { terms of income?" (livelihood category*) }\end{array}$ \\
\hline $\begin{array}{l}\text { HH Dependence on } \\
\text { Marine for Livelihoods }\end{array}$ & $\begin{array}{l}\text { Household income (Thai baht) from fisheries calculated from table in } \\
\text { household survey identifying monthly incomes by sector and season (n) }\end{array}$ \\
\hline HH Income & $\begin{array}{l}\text { Overall household income (Thai baht) calculated from table in survey } \\
\text { identifying overall monthly incomes }(\mathrm{n})\end{array}$ \\
\hline $\begin{array}{l}\text { Number of } \mathrm{HH} \\
\text { appliances }\end{array}$ & $\begin{array}{l}\text { Sum (n) of the responses to the following survey question: "Which of the } \\
\text { following items does the household possess. Check all that apply: a) Clay } \\
\text { stove } \\
\text { b) Gas stove, c) Fridge, d) Television, e) Radio, f) Cell phone, g) Computer, } \\
\text { h) Air conditioner" }\end{array}$ \\
\hline $\begin{array}{l}\text { HH Land ownership for } \\
\text { livelihood purposes }\end{array}$ & $\begin{array}{l}\text { Survey question: "Do people in your household own other land that is } \\
\text { suitable for livelihood purposes - either agriculture, plantations, or } \\
\text { tourism?" (Y/N) }\end{array}$ \\
\hline $\begin{array}{l}\text { Primary occupation of } \\
\text { interviewee* }\end{array}$ & $\begin{array}{l}\text { Survey question: Primary occupation of the interviewee (livelihood } \\
\text { category*) }\end{array}$ \\
\hline Age of interviewee & Survey question: Age of the interviewee (n) \\
\hline Gender of interviewee & Survey question: Gender of the interviewee $(\mathrm{M} / \mathrm{F})$ \\
\hline $\begin{array}{l}\text { Level of formal } \\
\text { education of interviewee }\end{array}$ & $\begin{array}{l}\text { Survey question: Formal education identified by category: 1) none, 2) 1-3, } \\
\text { 3) 4-6, 4) middle school, 5) high school, 6) diploma or vocational certificate, } \\
\text { 7) bachelors, 8) graduate program }\end{array}$ \\
\hline $\begin{array}{l}\text { Occupational Mobility of } \\
\text { interviewee }\end{array}$ & $\begin{array}{l}\text { Survey question: "How many different occupations have you had in the past } \\
10 \text { years?" (n) }\end{array}$ \\
\hline $\begin{array}{l}\text { Individual mobility of } \\
\text { interviewee }\end{array}$ & Survey question: "How many years have you lived in this community?" (n) \\
\hline $\begin{array}{l}\text { Social capital - Level of } \\
\text { community involvement } \\
\text { (interviewee) }\end{array}$ & $\begin{array}{l}\text { Sum (n) of the responses to the following survey question: "In which of the } \\
\text { following ways are you involved with community organizations? Check all } \\
\text { that apply: a) Attend meetings and listen, b) Attend meetings and express } \\
\text { opinions, c) Active membership in an organization, d) Member of } \\
\text { committee, and e) Elected member of leadership" }\end{array}$ \\
\hline $\begin{array}{l}\text { Number of sources that } \\
\text { learned about climate } \\
\text { change (interviewee) }\end{array}$ & $\begin{array}{l}\text { Sum (n) of the climate change sources from the survey question: "Have you } \\
\text { learned about climate change from any of the following sources? Check all } \\
\text { that apply: a) Newspapers, b) Radio, c) Television, d) Internet, e) Visiting } \\
\text { Non-Governmental Organizations, f) Going on a fieldtrip or to a workshop, } \\
\text { g) Community Leaders, h) Schools-teachers, i) Visiting climate scientists- } \\
\text { experts, j) Family or friends, k) Government information, l) Other" }\end{array}$ \\
\hline
\end{tabular}

Note: *Although the survey contained 34 individual livelihoods, for the purposes of this analysis, we recoded livelihoods to the following categories: fisheries, tourism, agriculture and plantations, other (i.e., govt. employee, store, construction, community cooperative, recycling), subsistence, and unemployed or student. 